\title{
Isolated right ventricular hypoplasia
}

INSERM

\section{Source}

INSERM. (1999). Orphanet: an online rare disease and orphan drug data base. Isolated right ventricular hypoplasia. ORPHA:439

Isolated right ventricular hypoplasia (IRVH) is a rare congenital heart malformation (see this term) characterized by underdevelopment of the right ventricle associated with patent foramen ovale or interauricular communication (see these terms) and normally developed tricuspid and pulmonary valves. IRVH manifests with severe cyanosis, congestive heart failure, and in severe cases, death in early infancy. 